\title{
USABILITY TESTING MENGGUNAKAN METODE HEURISTIC EVALUATION PADA APLIKASI E-MUSRENBANG BAPPEDA KABUPATEN BADUNG
}

\author{
Ni Ketut Thrisnandha Purnama1), I Made Ardwi Pradnyana'), Ketut Agustini ${ }^{3)}$ \\ ${ }^{1}$ Fakultas Teknik Dan Kejuruan, Universitas Pendidikan Ganesha \\ Email: nandha.purnama@gmail.com, ardwi.pradnyana@undiksha.ac.id, ketut.agustini@undiksha.ac.id
}

\begin{abstract}
ABSTRAK
Penelitian ini bertujuan untuk mengetahui hasil usability pada aplikasi E-Musrenbang Bappeda badung, serta memberikan rekomendasi rancangan pada aplikasi EMusrenbang Bappeda Badung yang memenuhi kriteria usability. Metode pengumpulan data yang digunakan yaitu dengan metode Heuristic Evaluation dari Jacob Nielsen dengan 10 kriteria usability yaitu variabel visibility of system status, match between system and the real world, user control and freedom, consistency and standards, recognition rather than recall, flexibility and efficiency of use, aesthetic and minimalist design, help users recognize, diagnose and recover from errors, help and documentation. Kuesioner awal dilakukan uji validitas dengan formula gregory yang melibatkan ahli sistem, dan ahli bahasa. Hasil data kemudian dianalisis dengan melakukan uji validitas, uji reliabilitas, dan uji heuristik. Hasil penelitian menunjukkan hasil analisa kuesioner sehingga didapat hasil bahwa layout sistem aplikasi EMusrenbang sudah mampu memenuhi kriteria usability sebuah sistem informasi. Sehingga dalam penelitian ini rekomendasi berdasarkan hasil kuesioner yang memiliki persentase rendah dan panduan perbaikan layout didasarkan pada panduan $\mathrm{HCl}$. Hasil persentase tertinggi sebesar $77 \%$ yaitu variabel Flexibility and Efficiency of Use dan persentase terendah yaitu variabel Recovery and System memiliki persentase $57 \%$, dan dari 15 responden didapatkan tingkat persentase usability sistem aplikasi E-Musrenbang Bappeda Badung sebesar $64 \%$ yang masuk dalam kategori tinggi sehingga memenuhi kriteria usability pada suatu sistem aplikasi.
\end{abstract}

Kata kunci : usability, evaluasi heuristik, E-Musrenbang, Bappeda,

\begin{abstract}
The study aims to determine the results of usability in the application of the $E$ Musrenbang Bappeda Badung, and provide design recommendations on the application of the E-Musrenbang Badung Bappeda that meets the usability criteria. The data collection method used is the Heuristic Evaluation method from Jacob Nielsen with 10 usability criteria, namely the visibility of system status variable, the match between system and the real world, user control and freedom, consistency and standards, rather than recall recognition, flexibility and efficiency of use, aesthetic and minimalist design, help users recognize, diagnose and recover from errors, help and documentation. The initial questionnaire was tested for validity with a gregory formula involving system experts, and linguists. The results of the data are then analyzed by conducting validity tests, reliability tests, and heuristic tests. The results of the study show the results of questionnaire analysis so that the results obtained that the layout of the E-Musrenbang application system has been able to meet the usability criteria of an information system. So in this study the recommendations are based on the results of a questionnaire that has a low percentage and guidelines for repairing layouts based on the $\mathrm{HCl}$ guidelines. The highest percentage results were $77 \%$, namely the variable Flexibility and Efficiency of Use and the lowest percentage, namely the Recovery and System variable with a percentage of $57 \%$, and from 15 respondents the percentage usability level of the E-Musrenbang Bappeda Badung application system was $64 \%$ in the high category so meet the usability criteria in an application system.
\end{abstract}

Keywords : usability, heuristic evaluation, E-Musrenbang, Bappeda 


\section{PENDAHULUAN}

Pengembangan teknologi yang semakin pesat di era digital saat ini membuat seluruh pengguna mengikuti alur perkembangan. Hal tersebut dapat dilihat dari kegiatan manusia yang memanfaatkan teknologi untuk memudahkan dalam melakukan suatu pekerjaan. Salah satu pemanfaatan teknologi informasi yaitu instansi pemerintahan Bappeda Kabupaten Badung menyusun suatu pengembangan sistem aplikasi perencanaan pembangunan daerah bernama E-Musrenbang. Aplikasi E-Musrenbang merupakan salah satu produk yang digunakan untuk melakukan proses perencanaan pembangunan secara online dan dapat diakses oleh semua masyarakat, dengan adanya sistem ini maka proses pembangunan Kabupaten Badung akan dapat terencana dengan baik. Dengan memperhatikan pengguna maka dapat diciptakan suatu sistem informasi yang sesuai dan tepat bagi pengguna, sehingga akan menimbulkan suatu kepuasan oleh para pengguna.

Pembuatan suatu sistem informasi harus dilakukan dengan memperhatikan faktor kemudahan penggunaan (usability). Usability adalah suatu ilmu rekayasa (engineering) dalam rekayasa usability telah didefinisikan metode-metode yang sangat sistematis (Nielsen, 2002) dan usability masih merupakan cabang ilmu yang relatif baru. Dalam hal pengujian [1] mendefinisikan usability testing dalam kaitannya dengan setiap teknik guna mengevaluasi produk atau sistem. Pengujian kegunaan adalah proses yang mempekerjakan orang sebagai peserta tes yang mewakili target audiens untuk menilai sejauh mana produk memenuhi kriteria kegunaan tertentu. Pengujian kegunaan merupakan bagian dari upaya untuk meningkatkan profitabilitas produk. Selain itu, keputusan desain yang diinformasikan oleh data yang dikumpulkan dari pengguna representatif untuk mengekspos masalah desain yang dapat diperbaiki, sehingga meminimalkan atau menghilangkan frustasi bagi pengguna.

Salah satu masalah yang dihadapi dalam pengembangan aplikasi adalah berkaitan dengan interface atau desain antarmuka. Salah satu cara mengevaluasi desain antarmuka dengan menggunakan pengujian usability Heuristic Evaluation. Heuristic Evaluation merupakan metode untuk mengukur sejauh mana problem usability (kegunaan) sebuah perangkat lunak dalam desain antarmuka. Identifikasi masalah usability ini berada di bidang interaksi manusia dan komputer. Penelitian ini ditunjukkan untuk pegawai atau staf di Bappeda Kabupaten Badung yang mengakses aplikasi E-Musrenbang. Metode Heuristic Evaluation dari Jacob Nielsen dengan 10 kriteria usability yaitu visibility of system status, match between system and the real world, user control and freedom, consistency and standards, recognition rather than recall, flexibility and efficiency of use, aesthetic and minimalist design, help users recognize, diagnose and recover from errors, help and documentation. Tujuan dilakukan penelitiannya ini untuk mengetahui sejauh mana tingkat usability dari sistem dan memberikan rekomendasi perbaikan sistem aplikasi E-Musrenbang Bappeda Badung.

Hasil penelitian ini diharapkan dapat bermanfaat bagi pengembang sistem memperoleh rekomendasi perbaikan sistem aplikasi E-Musrenbang Bappeda Kabupaten Badung berdasarkan pengujian usability, sehingga dapat dilakukan perbaikan pada bagian sistem yang dimaksud dan dapat membantu instansi dalam mengevaluasi aplikasi E-Musrenbang Bappeda Kabupaten Badung.

\section{METODE}

1. Jenis Penelitian

Jenis penelitian ini adalah penelitian survei sedangkan metodenya adalah deskriptif analitis. Menurut [2] metode survei deskriptif berupaya menjelaskan atau mencatat kondisi atau sikap untuk menjelaskan apa yang ada saat ini. Tujuan dari penelitian deskriptif adalah untuk membuat deskripsi secara sistematis, faktual dan akurat mengenai fakta-fakta dan sifat populasi tertentu [3]. Jadi dalam penelitian ini akan dilakukan analisa secara deskriptif untuk mengukur tingkat usability pada website dengan menggunakan metode heuristic evaluation yang didasari pada fakta yang terjadi.

\section{Lokasi dan Waktu Penelitian}

Lokasi penelitia ini dilaksanakan di Badan Perencanaan Pembangunan (Bappeda) Daerah Pusat Pemerintahan Kabupaten Badung, dan waktu pelaksanaan penelitian ini dimulai sejak Desember 2018 sampai Juli 2019.

\section{Prosedur Penelitian}


Prosedur penelitian merupakan langkah-langkah yang ditempuh dalam melakukan suatu penelitian, untuk mendapatkan infomasi yang dapat menjawab pertanyaan peneliti. Prosedur penelitian dilaksanakan untuk dapat mengungkapkan secara tuntas terkait permasalahan yang diajukan dalam penelitian. Adapun prosedur dalam penelitian ini seperti dikutip dari [4]. Adapun prosedur penelitian dapat disajikan pada gambar 1 .

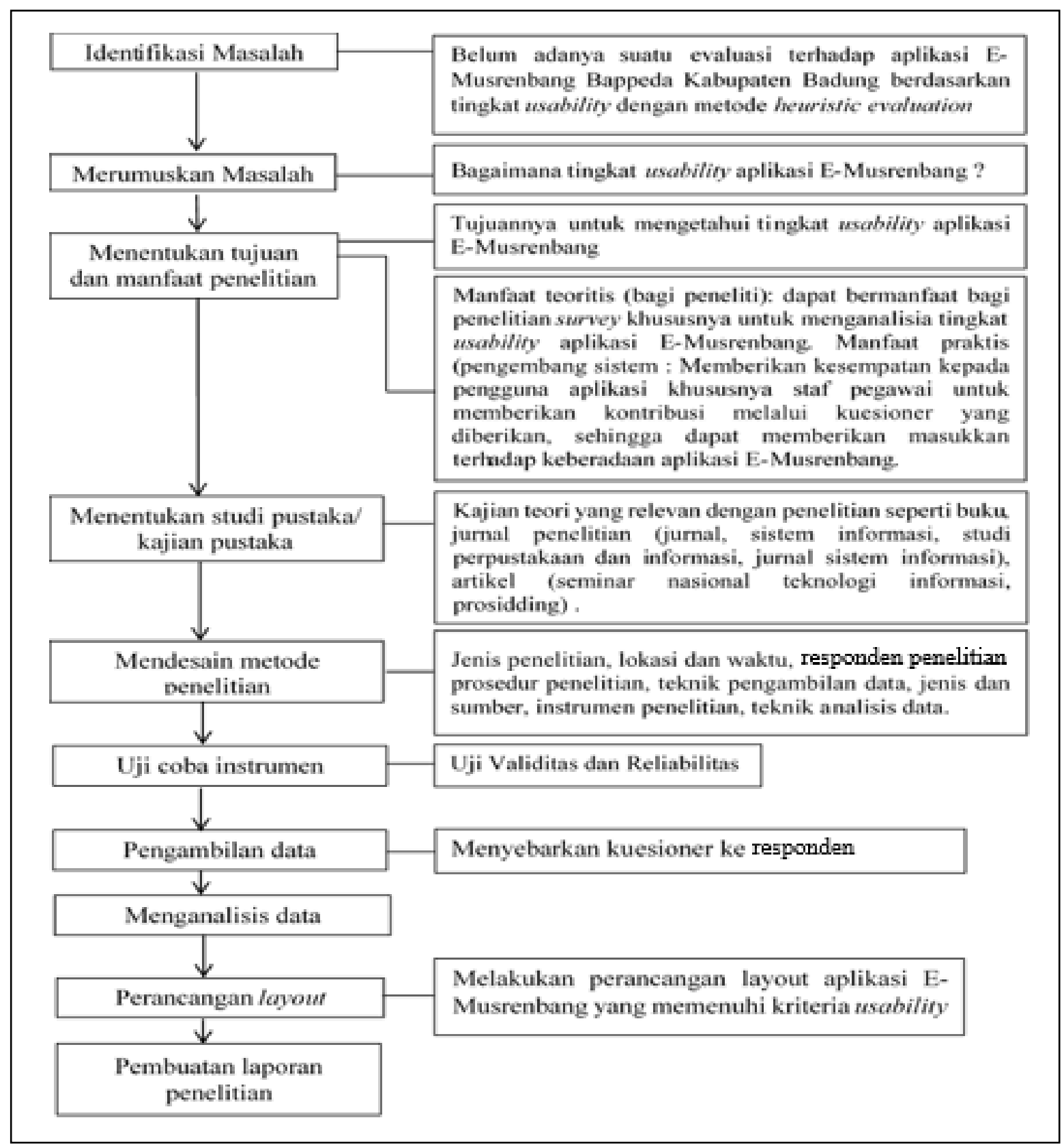

4. Responden Penelitian

Gambar 1 Prosedur Penelitian

Subjek yang diteliti adalah staf pegawai Bappeda Badung yang terlibat langsung dengan sistem aplikasi E-Musrenbang. Dalam buku Usability Testing for Survey Research yang ditulis oleh [5] menjelaskan bahwa 15 orang responden dibutuhkan untuk mengidentifikasi seluruh permasalahan usability. Dengan 8 orang responden dapat mengidentifikasi sekitar $95 \%$ permasalahan usability, dan 7 responden tambahan untuk mengidentifikasi $5 \%$ masalah terakhir.

5. Teknik Pengumpulan Data 
Teknik pengumpulan data adalah usaha sadar untuk mengumpulkan data yang dilakukan secara sistematis dengan prosedur terstandar. Teknik pengumpulan data yang digunakan dalam penelitian ini adalah :

a. Dokumentasi

Metode dokumentasi yaitu salah satu cara mencari data mengenai hal-hal atau variabel yang berupa catatan, transkrip, buku, surat kabar, majalah, prasasti, dan sebagainya [6]. Pada penelitian ini, peneliti menggunakan dokumentasi sebagai sarana untuk mendapatkan data yang diinginkan.

b. Kuesioner

Kuesioner merupakan teknik pengumpulan data yang dilakukan dengan cara memberi seperangkat pertanyaan atau pernyataan tertulis kepada responden untuk dijawabnya [7]. Cara pengumpulan data dengan menggunakan daftar pertanyaan yang telah disiapkan dan disusun sedemikian rupa sehingga calon responden hanya mengisi atau menandainya dengan mudah dan cepat. Kuesioner dalam penelitian ini merupakan kumpulan pertanyaan dalam penggunaan sistem aplikasi E-Musrenbang terkait dengan usability yang disebar ke responden penelitian.

6. Jenis dan Sumber Data

Jenis data dalam penelitian ini terdiri dari data kualitatif dan kuantitatif. Menurut (Sugiyono, 2012) metode penelitian kuantitatif kualitatif dan analisis data adalah proses mencari dan menyusun data yang diperoleh secara sistematis, dengan cara mengorganisasikan data ke dalam kategori, menjabarkan ke dalam unit-unit, melakukan sintesa, menyusun ke dalam pola, memilih mana yang penting dan yang akan dipelajari, serta membuat kesimpulan sehingga mudah dipahami oleh diri sendiri maupun orang lain. Sumber data dalam penelitian ini terdiri data primer dan data skunder.

7. Instrumen Penelitian

Dalam penelitian ini instrumen yang digunakan adalah dalam bentuk kuesioner (angket)

8. Uji Coba Instrumen

Pada uji coba instrumen dilakukan pengujian terhadap item-item pernyataan yang terdapat pada kuesioner yaitu menggunakan uji validitas dan reliabilitas. Item kuesioner diujicobakan sejumlah 90 butir dan menggunakan ukuran validitas konstruk.

9. Teknik Analisis Data

Analisis data adalah proses mencari dan menyusun data yang diperoleh secara sistematis dengan cara mengorganisasikan data ke dalam kategori, menjabarkan ke dalam unit-unit, melakukan sintesa, menyusun ke dalam pola, memilih mana yang penting dan yang akan dipelajari, serta membuat kesimpulan sehingga mudah dipahami oleh diri sendiri maupun orang lain. Dalam penelitian ini menggunakan analisis kuantitatif dan kualitatif dan analisis kesuksesan. Analisis kuantitatif bertujuan untuk memperoleh persentase dari hasil kuesioner yang dianalisis secara deskriptif. Analisis kuantitatif bertujuan untuk menganalisi metode yang diganakan yaitu Heuristic Evaluation. Hasil perhitungan persentase digunakan skala sebagai pedoman pendeskripsian usability sistem aplikasi EMusrenbang. Setelah didapatkan persentase jawaban responden selanjutnya diberikan penafsiran atau penilaian terhadap hasil penelitian. Peneliti menggunakan metode penafsiran seperti tabel 1 berikut:

Tabel 1. Kategori Nilai Persentase

\begin{tabular}{cll}
\hline NO. & PERSENTASE BATAS INTERVAL & KATEGORI PENILAIAN \\
\hline 1 & $0-20 \%$ & Sangat rendah \\
2 & $21-40 \%$ & Rendah \\
3 & $41-60 \%$ & Sedang \\
4 & $61-80 \%$ & Tinggi \\
5 & $81-100 \%$ & Sangat Tinggi
\end{tabular}




\section{HASIL DAN PEMBAHASAN}

Penelitian ini mengumpulkan hasil jawaban kuesioner dari 15 orang staf pegawai Bappeda sebagai responden. Deskripsi data berisi rata-rata persentase jumlah responden, yang meliputi ratarata persentase responden yang memilih pilihan sangat setuju (SS), setuju (S), kurang setuju (KS), tidak setuju (TS) dan untuk mengukur kategori tingkat kegunaan dari setiap indikator yaitu Visibility Match Between System and The Real World, User Control ad Freedom, Consistency and Standards, Recognition Rather than Recall, Flexibility and Efficiency of Use, Design, Recovery and System dan Help and Documentation. Dari seluruh responden penelitian yang telah ditentukan, maka didapatkan hasil persentase pada masing-masing variable metode heuristic evaluation.

1. Hasil Uji Gregory

Perhitungan uji validitas isi dilakukan dengan formula Gregory dengan melibatkan 2 orang pakar. Hasil penilaian dari kedua pakar adalah 54 jawaban dinyatakan relevan, jadi koefisien validitas isi instrument yang diuji coba adalah 0.60 yang berkategori tinggi. Untuk instrument yang dinilai tidak relevan telah diperbaiki sehingga semua instrument dapat diujicobakan.

2. Hasil Uji Validitas

Uji Validitas adalah suatu ukuran yang menunjukkan tingkat kevalidan suatu instrumen. Instrumen dikatakan valid apabila instrumen tersebut dapat mengukur apa yang seharusnya diukur secara tepat [6]. Pengujian validitas kosntruk untuk instrument menggunakan rumus korelasi Pearson Product Moment. Dalam penelitian ini kuesioner telah diujicobakan ke 20 responden awal. Hasil perhitungan menggunakan Microsoft Excel 2013 dan Aplikasi SPSS 20, dengan butir instrumen yang diujicobakan berjumlah 90 butir, 38 butir pertanyaan dinyatakan tidak valid dan 52 butir dinyatakan valid. Syarat minimum untuk dianggap suatu butir instrument dinyatakan valid adalah nilai indeks validitasnya $>0.444$. Oleh karena itu semua pertanyaan yang memiliki korelasi dibawah 0.444 dinyatakan tidak valid [8] kemudian pertanyaan yang tidak valid, tidak diperbaiki dan tidak diujicoba kembali melainkan langsung dihilangkan.

3. Hasil Uji Reliabilitas

Uji reliabilitas dilakukan untuk menguji derajat konsistensi atau stabilitas instrumen dalam interval tertentu. Hasil penelitian yang reliabel bila terdapat kesamaan data dalam waktu yang berbeda. Reliabilitas menunjukkan pada suatu pengertian bahwa sesuatu instrumen cukup dan dapat dipercaya untuk digunakan sebagai alat pengumpulan data karena instrumen sudah baik [6]. Perhitungan uji reliabilitas menggunakan aplikasi SPSS 20. Berdasarkan uji coba instrumen kepada 20 orang responden, diperoleh hasil perhitungan reliabilitas menggunakan rumus Alpha Cronbach sebesar 0.937 dari 90 butir pertanyaan yang berkategori sangat tinggi.

4. Hasil Uji Heuristic

Hasil uji heuristic evaluation berdasarkan gambar 2 dari responden staf pegawai Bappeda didapatkan variabel terbesar yaitu variabel Flexibility and Efficiency of Use dengan persentase $77 \%$ kemudian variabel Design yang memiliki persentase sebesar $70 \%$, variabel Consistency and Standard dengan persentase 69\%, variabel Visibility yang memiliki pesentase 66\%, variabel Match Between and The Real World dengan persentase 65\%, kemudian variabel Recognition Rather Than Recall memiliki persentasi $64 \%$, variabel Prevention Error System dengan persentase 62\%, variabel User Control and Freedom dengan persentase sebesar 59\%, variabel Help and Documentation memiliki persentase yaitu $57 \%$, dan Recovery and System memiliki persentase terkecil yaitu $57 \%$. 


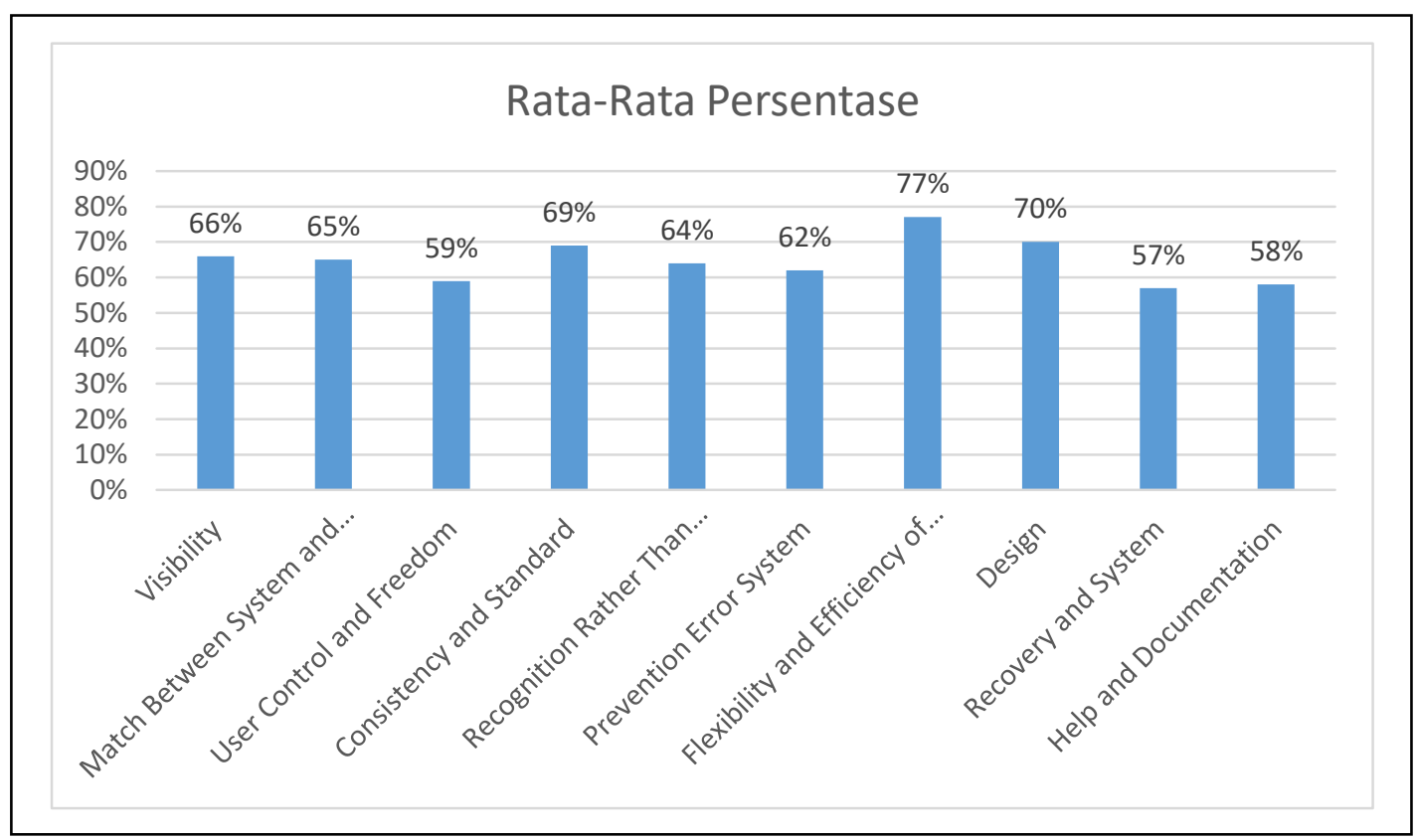

Gambar 2. Diagram Persentase Variabel Metode Heuristic Evaluation

Menurut hasil penelitian yang dilakukan peneliti, persentase variabel tertinggi yaitu Flexibility and Efficiency of Use yang meliputi penawaran bahasa yang berbeda dan sistem sesuai untuk screen reading, karena dilihat bahwa dari sistem aplikasi EMusrenbang cukup menggunakan satu bahasa saja yaitu Bahasa Indonsia yang sudah digunakan pada sistem aplikasi E-Musrenbang saat ini dan pada sistem aplikasi EMusrenbang memang belum disajikan screen reading untuk mempermudah pengguna untuk membaca menu ataupun iaspirasi yang terdapat di sistem aplikasi E-Musrenbang. Jika dilihat dari variabel terkecil yaitu variabel Recovery and System, berdasarkan jawaban dari responden staf pegawai Bappeda menyatakan bahwa jika terjadi kesalahan pada sistem aplikasi E-Musrenbang perlu adanya pemberitahuan secara langsung pada sistem dan diharapkan admin dapat memberikan pelayanan yang optimal ketika terjadi kesalahan pada sistem.

Hasil rata-rata tiap variabel pada metode heurstic evaluation pada hasil penelitian kuesioner, maka dapat dicari rerata persentase tingkat usability sistem aplikasi EMusrenbang dengan kalkulasi dari 10 variabel, maka dari kalkulasi hasil rata-rata 10 variabel metode heuristic evaluation, didapatkan hasil rata-rata tingkat usability sistem aplikasi E-Musrenbang, yaitu sebesar $64,41 \%$ yang dibulatkan menjadi $64 \%$, dan berdasarkan tabel 1 maka tingkat persentase tersebut masuk ke dalam tingkat usability tinggi.

Pembahasan yang didapat dari hasil kuesioner usability dengan menggunakan metode heuristic evaluation pada sistem aplikasi E-Musrenbang yang diketahui bahwa layout sistem aplikasi E-Musrenbang dari hasil responden staf pegawai Bappeda sudah mampu memenuhi kriteria usability sebuah sistem informasi. Namun dari informasi yang disajikan masih kurang lengkap dan kurang update. Sehingga dalam penelitian ini berdasarkan hasil kuesioner dan berdasarkan ilmu $\mathrm{HCl}$ rekomendasi perbaikan layout akan lebih difokuskan pada SOP (Standar Operasional Prosedur) pelayanan informasi yang jelas, cepat dan tepat pada sistem agar informasi yang disajikan pada sistem lebih lengkap dan terbaru. Selain itu, diharapkannya pelayanan yang cepat jika terjadi permasalahan pada sistem seperti terjadinya error pada halaman sistem.

Dari hasil analisa kuesioner didapat hasil bahwa layout sistem aplikasi EMusrenbang sudah mampu memenuhi kriteria usability sebuah sistem informasi. Sehingga dalam penelitian ini rekomendasi berdasarkan hasil kuesioner yang memiliki persentase rendah, dan didasarkan pada panduan $\mathrm{HCl}$ perbaikan layout lebih difokuskan pada penambahan informasi pada sistem aplikasi E-Musrenbang terjadi suatu kesalahan dan adanya bantuan untuk mempermudah pengguna dalam mencari solusi jika terdapat kelasahan dalam mengakses sistem. 
Berdasarkan pemaparan persentase variabel metode heuristic evaluation, maka dapat diberikan rekomendasi perbaikan pada sistem aplikasi E-Musrenbang:

1. Rekomendasi Perbaikan Menu Aspirasi Bagian Pemberitahuan

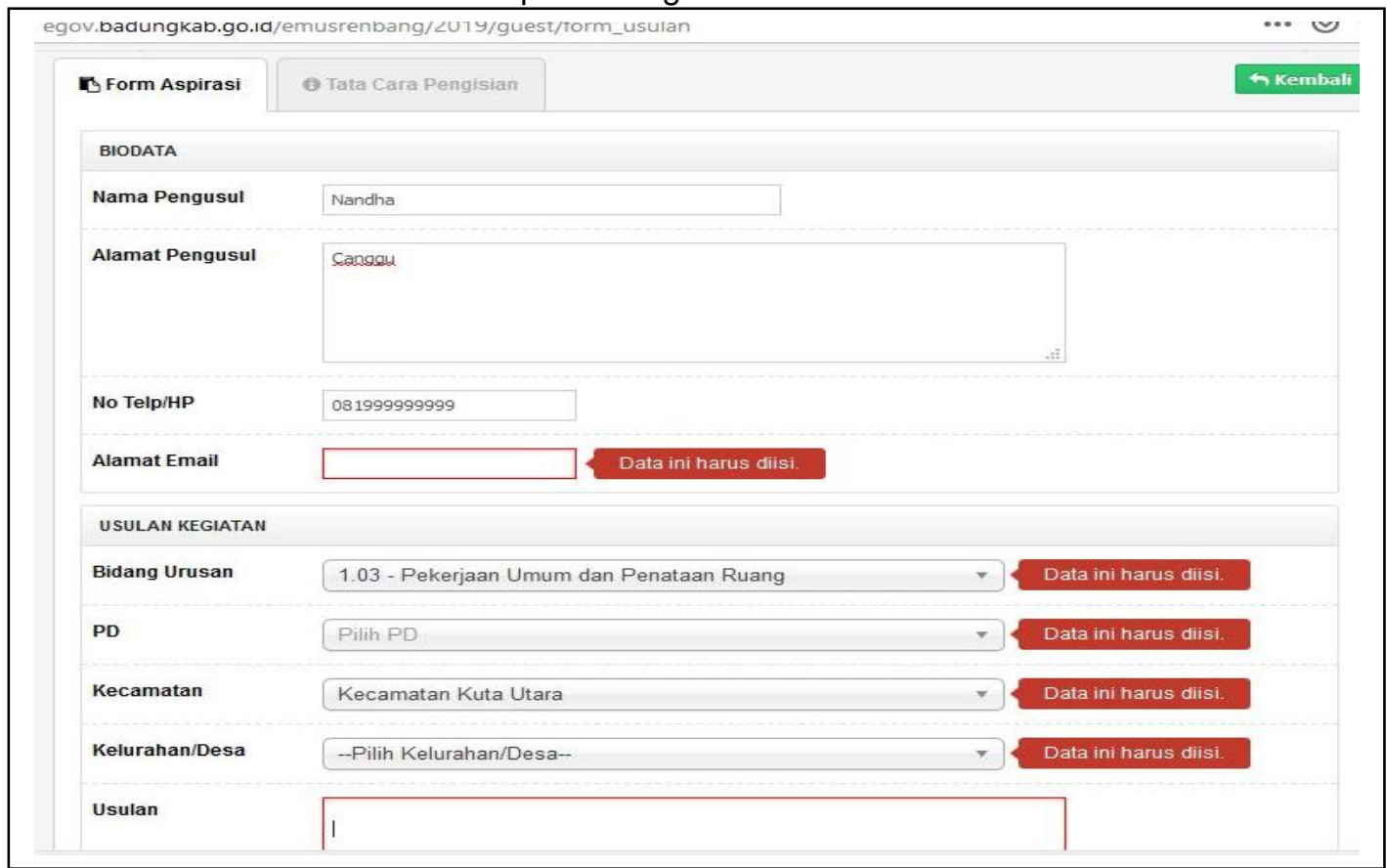

Gambar 3. Halaman Menu Form Aspirasi

Gambar 3 adalah tampilan halaman form aspirasi sistem Aplikasi E-Musrenbang Bappeda Badung sebelum dilakukan perubahan. Terdapat pemberitahuan jika ada kolom yang belum disi data maka akan diberikan notifikasi atau pemberitahuan namun tidak secara langsung saat sudah melewati proses isi data.

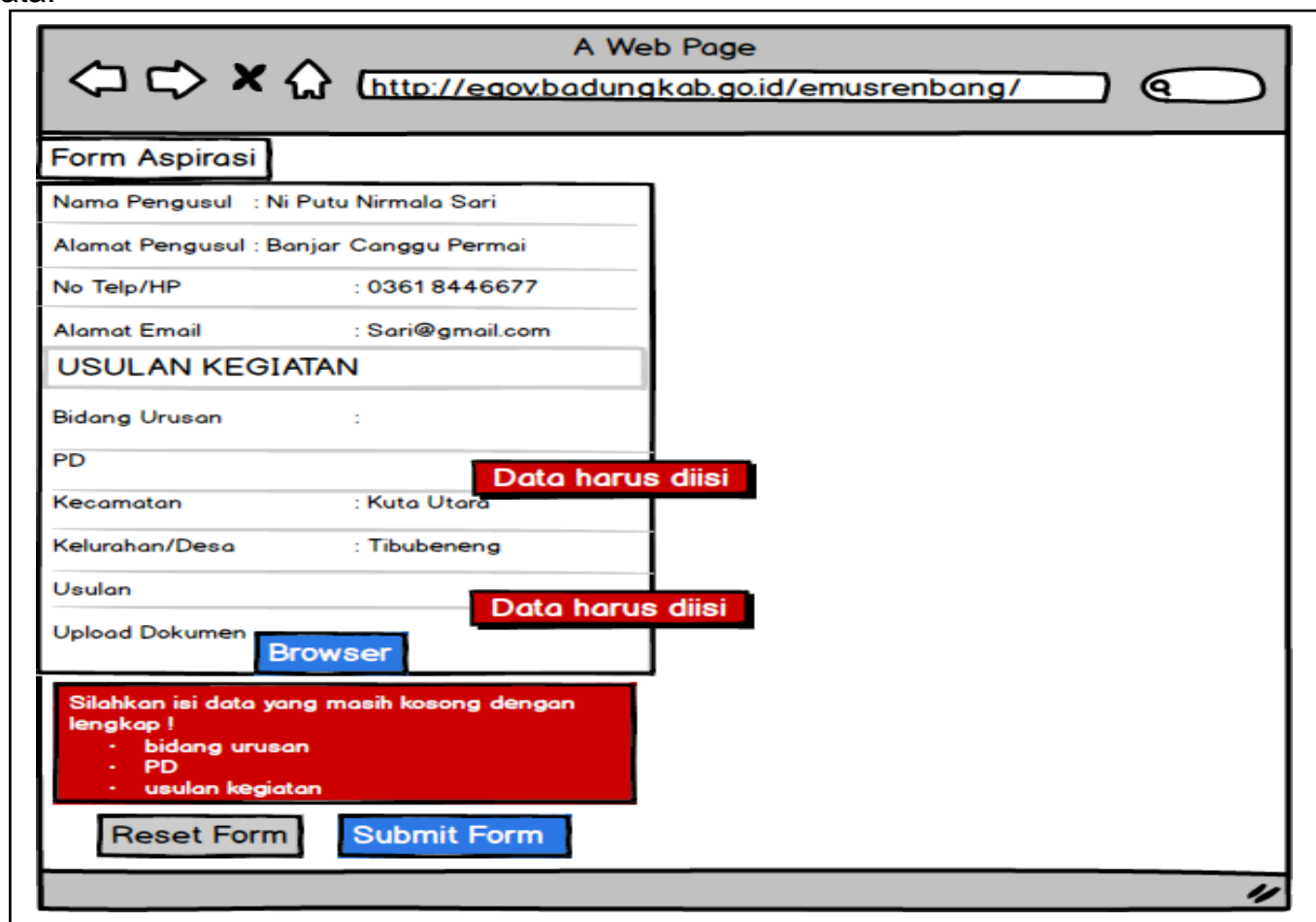

Gambar 4. Rekomendasi Perbaikan Menu Form Aspirasi 
Perubahan yang peneliti rekomendasikan serta penjelasan perubahan pada gambar 4 dijabarkan sebagai berikut:

a. Penambahan notifikasi ketika ada kesalahan, hal tersebut berkaitan dengan hasil persentase heuristic evaluation pada variabel Recovery and System dimana pada bagian halaman form aspirasi pada bagain bawah form aspirasi peneliti memberikan rekomendasi untuk memberi notifikasi data apa saja yang belum diisi dalam fom aspiras tersebut

\section{Rekomendasi Perbaikan Menu Dashboard}

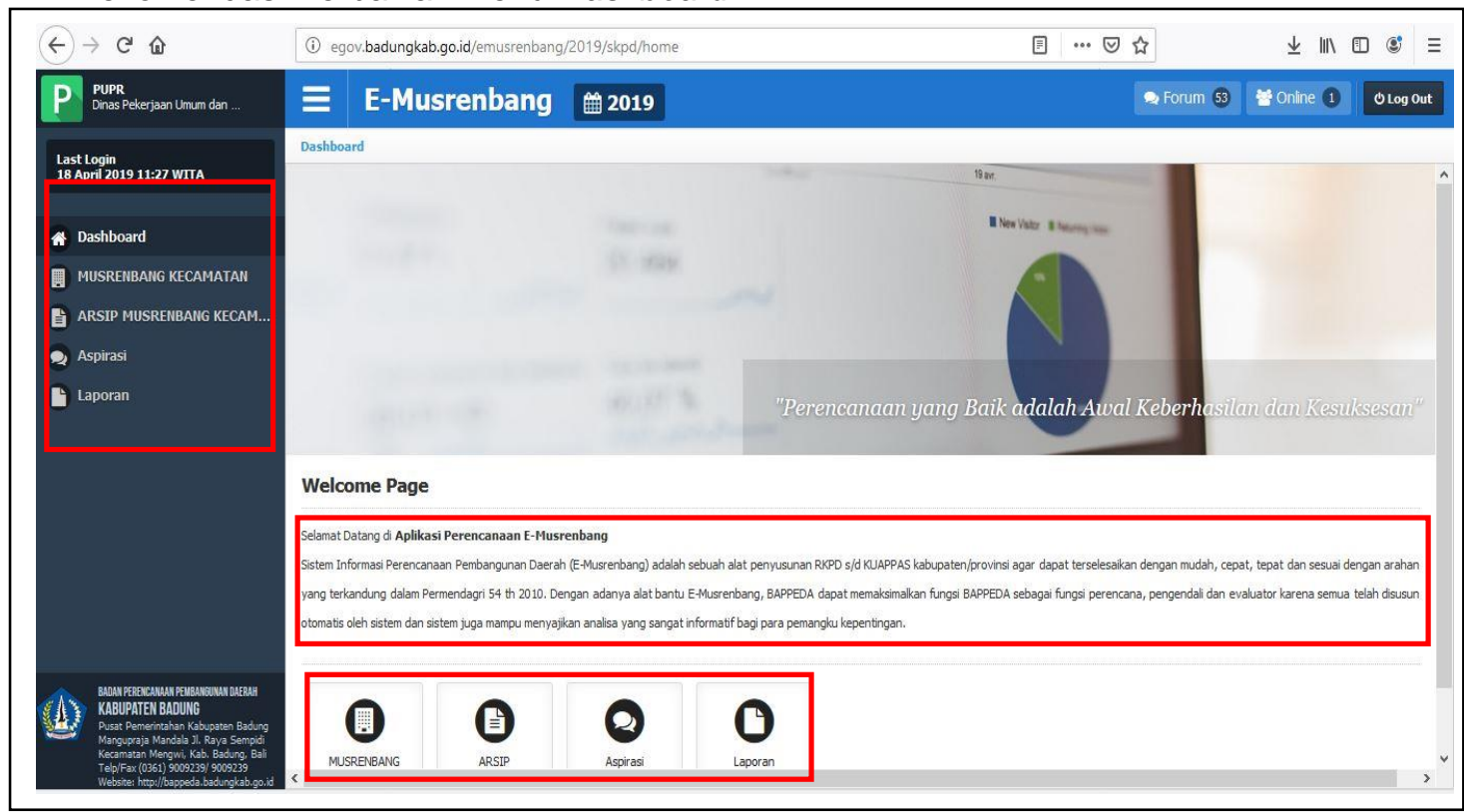

Gambar 5 Halaman Dashboard Sistem Aplikasi E-Musrenbang

Gambar 5 adalah tampilan halaman dashboard sistem Aplikasi E-Musrenbang Bappeda Kabupaten Badung sebelum dilakukan perubahan. Adapun pelanggaran yang terdapat pada halaman ini adalah redudansi menu dashboar, Musrebang Kecamatan, Arsip Musrenbang Kecamatan, Aspirasi dan Laporan serta font pada welcome page terlalu kecil. Adapun rancangan rekomendasi perbaikan pada halaman dashboard sistem aplikasi E-Musrenbang disajikan pada gambar 6.

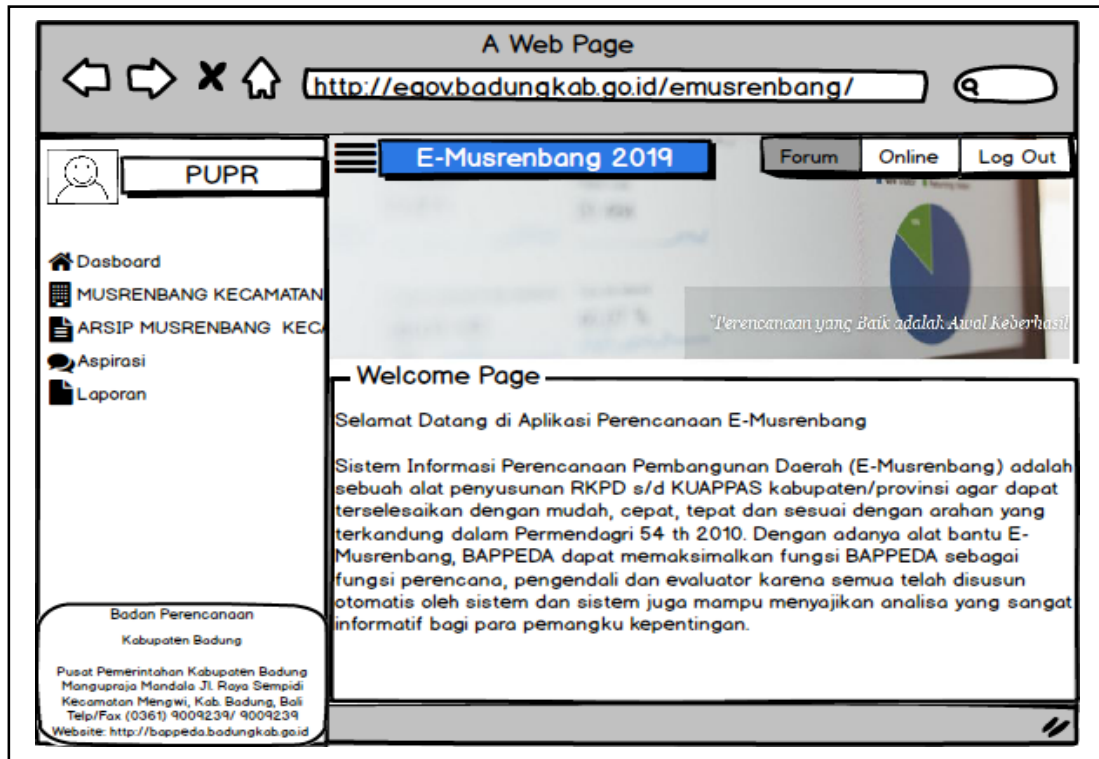

Gambar 6 rekomendasi Perbaikan Tampilan Dashboard 
Perubahan yang peneliti rekomendasikan serta penjelasan perubahan pada gambar 4.37 dijabarkan sebagai berikut:

a. Menghilangkan menu Dashboard, Arsip Musrenbang Kecamatan, Aspirasi dan Laporan pada bagian menu utama. adanya redudansi tombol dengan fungsi yang sama berpotensi menyebabkan pengguna mengalami kebingungan. Hal tersebut juga berlawanan dari teori pada buku Research-Based Web Design \& Usability Guidelines yang menyebutkan untuk tidak menyediakan dua atau lebih cara dengan informasi yang sama pada satu halaman website. Maka dari itu peneliti menghilangkan salah satu menu Dashboard, Arsip Musrenbang Kecamatan, Aspirasi dan Laporan.

b. Memperbesar ukuran font agar berukuran 14 berdasarkan aturan dari buku ResearchBased Web Design \& Usability Guidelines untuk menggunakan ukuran font setidaknya menggunakan font berukuran 12. Pertimbangan ini juga dilakukan atas saran dari responden bahwa font yang digunakan dirasa masih terlalu kecil dan perlu diperbesar untuk kenyamanan pengguna sistem.

3. Rekomendasi Perbaikan Pada Menu Forum

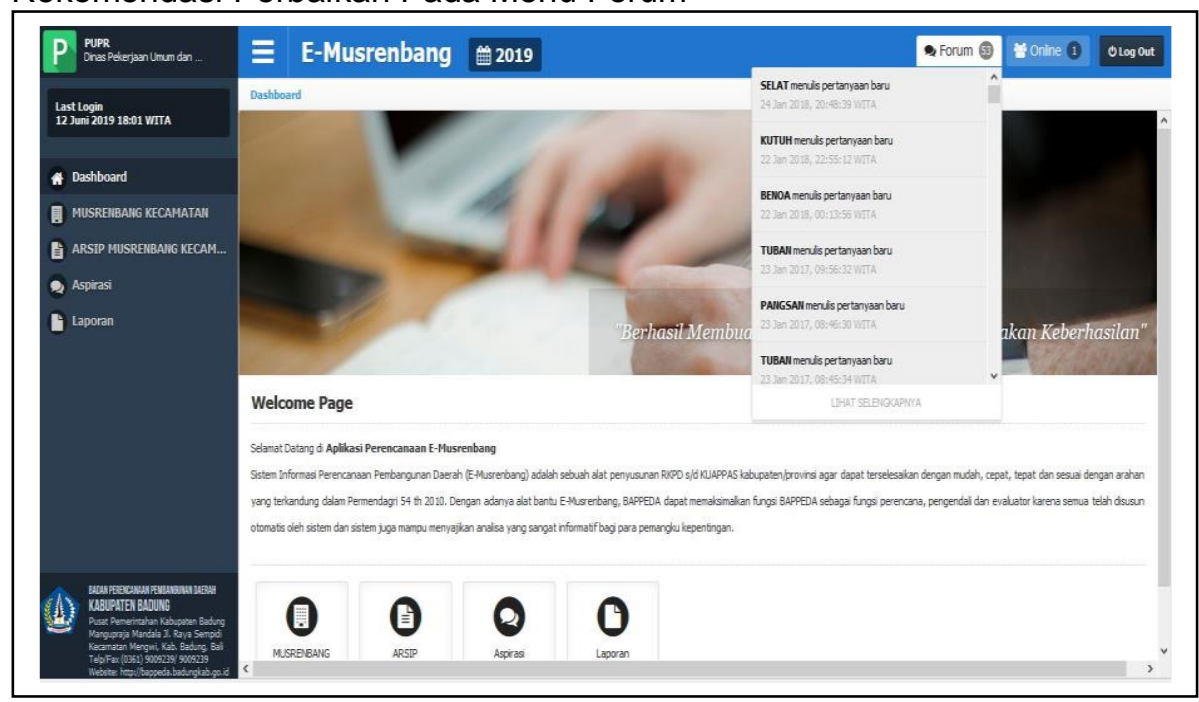

Gambar 7 Halaman Menu Dasbhoard Halaman Forum

Gambar 7 merupakan tampilan pada menu dashboard yang terdapat bagian menu Forum sebelum ada perubahan. Adapun pelanggaran yang terdapat pada halaman ini adalah font pada pemberitahuan forum terlalu kecil dan pemilihan warna font pada bagian tanggal dan keterangan waktu tidak sesuai. Disajikan pada gambar 8.

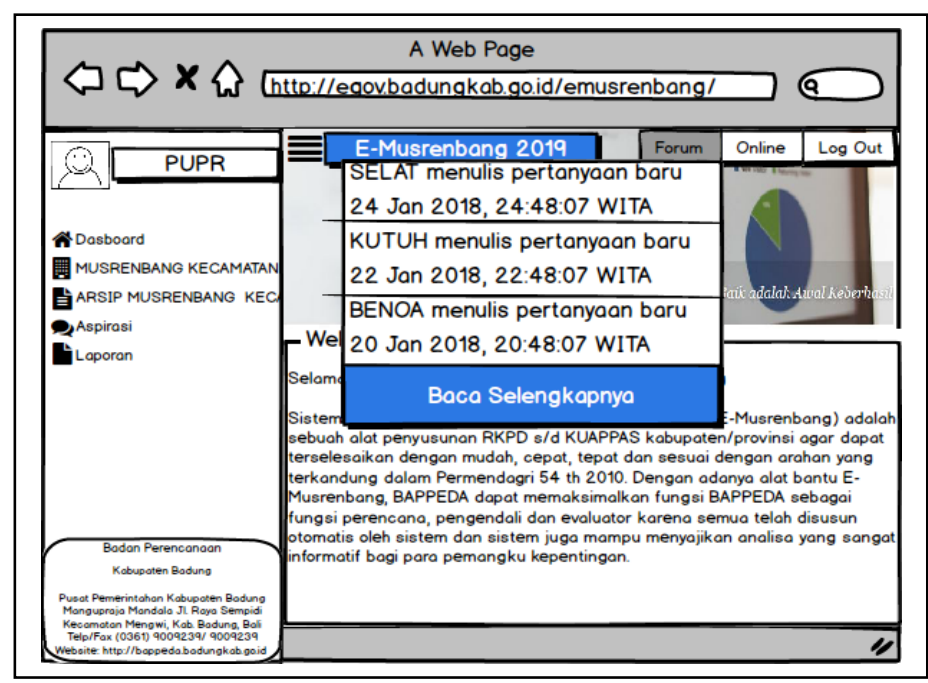

Gambar 8 Rekomendasi Perbaikan Halaman Forum 
Berdasarkan gambar 8 rancangan rekomendasi perbaikan peneliti lakukan adalah sebagai berikt:

a. Memperbesar ukuran font agar berukuran 14 berdasarkan aturan dari buku Research-Based Web Design \& Usability Guidelines untuk menggunakan ukuran font setidaknya menggunakan font berukuran 12. Pertimbangan ini juga dilakukan atas saran dari responden bahwa font yang digunakan dirasa masih terlalu kecil dan perlu diperbesar untuk kenyamanan pengguna sistem.

b. Mengganti warna font dengan font yang lebih gelap, jika dibandingkan dengan wana sebelumnnya, font warna abu-abu dengan kolom yang berwarna mendekati abu-abu sehingga font tidak begitu jelas terlihat dan terbaca. Rekomendasi ini berdasarkan aturan dari buku Research-Based Web Design \& Usability Guidelines yaitu orang akan membaca tulisan gelap $32 \%$ lebih cepat dari pada membaca tulisan terang.

4. Rekomendasi Perbaikan Pada Gallery Musrenbang Kecamatan

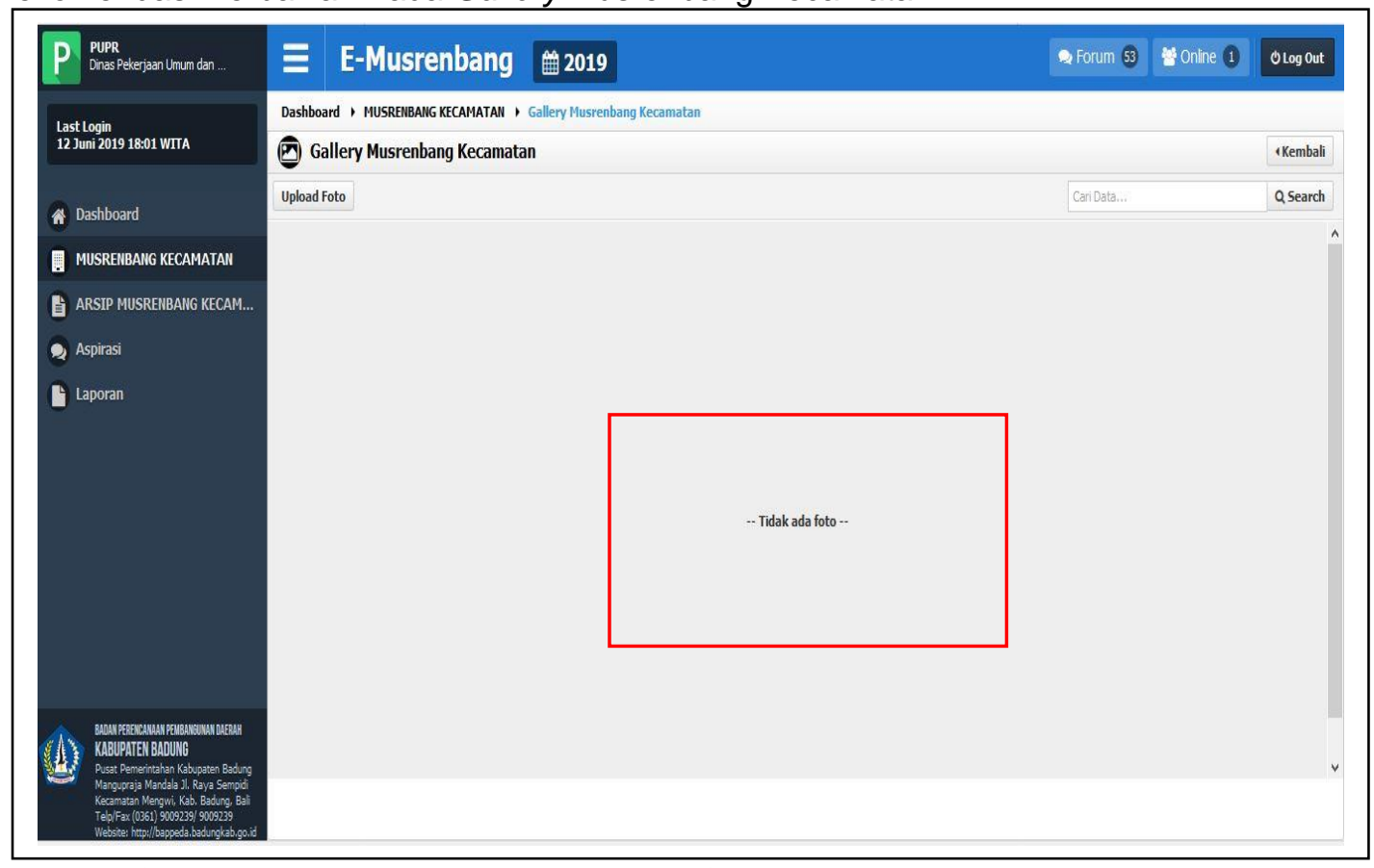

Gambar 9 Rekomendasi Perbaikan Menu Gallery Musrenbang Kecamatan

Rekomendasi perbaikan pada bagian gallery foto yaitu pada sistem sebaiknya diinputkan gambar atau foto kegiatan dari pengajuan aspirasi agar informasi yang disajikan semakin jelas diterima oleh pengguna.

\section{SIMPULAN DAN SARAN}

Berdasarkan deskripsi data, hasil penelitian dan analisa usability kuesioner dengan menggunakan metode Heuristic Evaluation yang telah dibahas secara deskriptif, maka simpulan dari peneliti adalah sebagai berikut :

1. Terdapat 10 variabel yang digunakan dalam penelitian ini yang diambil dari metode Heuristic Evaluation, yaitu, Visibility, Match Between System and The Real World, User Control and Freedom, Consistency and Standard, Recognition Rather Than Recall, Prevention Error System, Flexibility and Efficiency of Use, Design, Recovery and System, Help and Documentation. Dari 15 responden didapatkan tingkat usability sistem aplikasi E-Musrenbang Bappeda Badung sebesar $64 \%$ yang masuk dalam kategori tinggi.

2. Rekomendasi perbaikan dalam penelitian ini difokuskan untuk mengubah tata letak layout halaman yang didasari hasil data penyebab kesalahan error pada pengguna. Selain itu berdasarkan hasil dan saran pengguna melalui hasil penyebaran kuesioner dan wawancara perbaikan pada sistem aplikasi E-Musrenbang dengan membuat wifeframe pada halaman notifikasi ketika ada kesalahan, perubahan warna font, dan ukuran font pada beberapa halaman. 
berikut:

Beberapa saran yang dapat diajukan berkaitan dengan hasil penelitian ini adalah sebagai

1. Pada penelitian ini menggunakan metode Heuristic Evaluation untuk mengukur hasil ubsability pada sistem aplikasi E-Musrenbang. Hasil penelitian yang sudah dilakukan oleh peneliti menyatakan bahwa kondisi saat melakukan penyebaran kuesioner kepada responden tidak mengalami kendala, hanya saja proses pengumpulan responden perlu dilakukan secara terorganisir sehingga responden menerima perlakuan yang sama, seperti mendapatakan pengarahan diawal sebelum mengisi kuesioner, dan pengisian kuesioner yang dilakukan diwaktu yang sama.

2. Penelitian selanjutnya dapat menggunakan metode lain yang belum pernah digunakan untuk melakukan pengujian usability seperti metode Survei Ditempat (Onsite surveys), A/B Testing, Pelacakan Mata (Eye Tracking), Berfikir Keras-keras Menguji (Thingking Aloud Test), atau dengan Tes Buta Warna (Color Blind Test).

\section{DAFTAR PUSTAKA}

[1] Geisen, E. \& Bergstorm, J. R., Usability Testing for Survey Research, Cambridge: Elsevier Inc, 2017.

[2] I. Adnyana, Evaluasi Heuristic Antarmuka Aplikasi, 2017.

[3] A. Ali, E. Pramana and S. Tjandra, "EVALUASI HEURISTIK PADA WEB BASED LEARNING UNTUK MENINGKATKAN ASPEK USABILITY SISTEM," Jurnal Insand Comtech, Vol. 1, No. 1, 2016.

[4] U. Ependi, "HEURISTIC EVALUATION FOR MOBILE APPLICATION (STUDI KASUS: APLIKASI DEPO AUTO 2000 TANJUNG API API PALEMBANG)," Jurnal SIMETRIS, Vol 8 No 2, 2017.

[5] I. G. Harsemadi, I. B. Suradarma and I. P. W. Adnyana, "EVALUASI HEURISTIC ANTARMUKA APLIKASI PENGENALAN ARSITEKTUR BANGUNAN METEN BALI," Konferensi Nasional Sistem \& Informatika, 2017.

[6] P. Krisnayani, I. K. R. Arthana and I. G. M. Darmawiguna, "Analisa Usability Pada Website UNDIKSHA Dengan Menggunakan Metode Heuristic Evaluation," Kumpulan Artikel Mahasiswa Pendidikan Teknik Informatika (KARMAPATI), 2016.

[7] J. Nielsen, "Ten Usability Heuristics," August 2002. [Online]. Available: www.useit.com.

[8] B. Raharjo, Laporan Hasil Pekerjaan Update Aplikasi Perencanaan Pembangunan Daerah Badung Perancangan Pembangunan Daerah Kabupaten Badung, Badung, 2017.

[9] P. Savitri, "REVIEW DESAIN INTERFACE APLIKASI SOPPPOS MENGGUNAKAN," Jurnal SIMETRIS, Vol 6 No 1, 2015.

[10] I. M. A. O. Wijaya, I. K. R. Arthana and G. A. Pradnyana, "ANALISIS USER EXPERIENCE WEB BASED DIGITAL LIBRARY JURUSAN PENDIDIKAN TEKNIK INFORMATIKA," Kumpulan Artikel Mahasiswa Pendidikan Teknik Inforrmatika (KARMAPATI), 2017. 